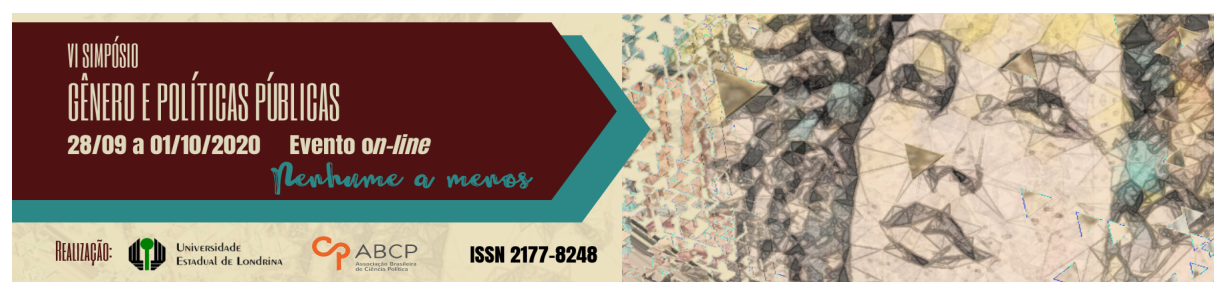

\title{
Moda e imprensa feminina: recursos para o ensino de história
}

\author{
Letícia Fernochi ${ }^{1}$
}

\section{Resumo}

Esse trabalho tem o intuito de analisar como a produção e divulgação de moda na revista feminina Jornal das Moças entre 1914 e 1920 pode ser utilizada como recurso para o ensino da disciplina de história na educação básica. Refletindo sobre o aumento da circulação de periódicos no Brasil no início do século XX pode-se perceber que a mulher ganha espaço na educação formal, na participação nos salões e leituras exclusiva para elas no que se julgava temas nos quais deveriam manter-se informadas. O periódico privilegiado nesse estudo é o Jornal das Moças com ênfase nas suas seções A arte de ser elegante e Modos e Modas, pois além das dicas de moda e gravura apresentadas os artigos discorrem um pouco sobre o contexto em que aquela vestimenta está sendo produzida, podendo ser uma fonte rica para o ensino de história.

Palavras-chave: moda. ensino de história; Jornal das Moças.

\section{Fashion and women's press: resources for teaching history}

\section{Abstract}

This article intends to analyze how the production and dissemination of fashion in the women's magazine Jornal das Moças between 1914 and 1920 can be used as a resource for teaching the discipline of history in basic education. Reflecting on the increased circulation of journals in Brazil in the early twentieth century, it is clear that women gain space in formal education, with the participation in salons and readings exclusively for them in what were considered topics in which they should keep informed. The privileged periodical in this study is the Jornal das Moças with an emphasis on its sections The Art of Being Elegant and Manners and Fashion, because in addition to the

1 Universidade Estadual de Maringá (UEM), mestranda do programa ProfHistória, le_fernochi@hotmail.com

GT 08 - Gênero, educação e escola 
fashion and print tips presented, the articles discuss a little about the context in which that garment is being produced, thus it can be a rich source for teaching history.

Keywords: fashion; history teaching; Jornal das Moças.

A moda como fonte de estudo para o ensino de história pode se dar em diversas perspectivas da confecção tanto das roupas como dos acessórios utilizados por uma sociedade. Partindo do princípio que a indumentária de um determinado período revela muito sobre ele, podemos trazer para as aulas e apresentar aos alunos documentos escritos ou imagéticos para desvendar o vínculo entre as roupas e os acontecimentos relevantes estudados de uma época, assim aproximamos os alunos das fontes históricas e mostramos a eles uma nova vertente de estudo.

Nessa pesquisa utilizaremos a definição de moda colocada por Daniela Calanca (2008, p. 12) que seria "fenômeno social da mudança cíclica dos costumes e dos hábitos, das escolhas e dos gostos, coletivamente validados e tornado obrigatório". A moda segundo Gilles Lipovetsky (2009, p. 31) quase não aparece até o século XIV, data em que se impõe após o aparecimento de um vestuário novo que diferenciava os sexos, curto e ajustado para os homens e longo e justo para as mulheres. Com o passar dos séculos a moda foi se alterando, mas no final do século XIX e início do século XX suas mudanças acontecem de maneira mais rápida possivelmente ligada ao modernismo tão incentivado no ocidente.

Um dos motivadores para se adotar as novidades da moda passa a ser facilmente a necessidade de afirmação, de mostrar que se pertence a um grupo, ela é um gênero de distinção social para a classe alta mas com o tempo e desenvolvimento de grandes magazines e novas formas de produção com preços mais acessíveis as outras classes também podem acessar. 


\section{A moda e o corpo em transformação}

Após a Primeira Guerra Mundial, segundo Lipovetsky (2009, p. 83), a confecção das roupas transformou-se devido a uma maior divisão do trabalho e a evolução da indústria química que possibilitou tecidos com um colorido mais rico. As coleções que anteriormente não tinham data fixa passam a se organizar pelas estações do ano e apresentam desfiles nos salões, no entanto até os anos 1960 a moda continua dependente dos decretos da alta costura parisiense.

Alta costura essa que disciplinou a moda atraindo cada vez mais compradores estrangeiros que adquiriam as coleções produzidas em Paris com o direito de reproduzir em série nos seus países de origem, assim as tendências ditadas pelos grandes nomes da alta costura vão se disseminando pelo mundo e tornando-se cada vez mais acessíveis, como se houvesse uma uniformização mundial da moda.

Ainda assim a moda também pode representar a individualidade observando os detalhes, os acessórios e modos de usar, a moda ligando não só o prazer de ver como o prazer de ser visto, a moda e seus códigos de elegância convidam a adaptação das novidades para cada corpo e personalidade (LIPOVETSKY, 2009, p. 43).

a moda trabalhou no refinamento do gosto e no aguçamento da sensibilidade estética; civilizou o olho, educando-o para discriminar as pequenas diferenças, para ter prazer nos pequenos detalhes sutis e delicados, para acolher as formas novas. [...] Norbert Elias notava como o universo de concorrência da corte despertava a arte de estudar os comportamentos e os motivos dos homens, acrescentemos que a moda empenhou-se nisso paralelamente, através da aparência e do gosto (LIPOVETSKY, 2009, p. 42).

As revistas femininas que são responsáveis pela divulgação das transformações ocorridas nas roupas já alertavam no início do século XX para suas leitoras realizarem as adaptações para adequação da vestimenta a sua individualidade, levando em consideração seu tipo de 
corpo e as estações do ano, além da retirada dos exageros. Na revista Jornal das Moças de 1 de julho de 1915, o artigo alerta para “só é legitima a moda que procura realçar a beleza natural ou então corrigir os defeitos. As modas não variam só com os paizes e estações do anno: variam de individuo a individuo".

Não só as roupas mudam mais os corpos chamados de belos também mudam com os imperativos da moda. No século XIX as mulheres elegantes eram as que possuíam um corpo ampulheta talhado por espartilhos e anquinhas que comprimiam ventre e costas projetando seios e nádegas. Já no início do século XX o famoso costureiro francês Paul Poiret rompe com o modelo anterior e a moda passa a ser a magreza. Além do que após a Primeira Guerra Mundial as "exuberâncias adiposas" passam a ser contidas não mais pelo espartilho mais pela cinta elástica (DEL PRIORE, 2000, p. 65).

Essa nova moda do corpo e da roupa também tiveram muita influência dos esportes, no período tratado nessa pesquisa a prática do golfe, tênis, bicicleta, banhos de mar, etc, tiveram um papel preponderante para as mudanças que se aceleraram após a Primeira Guerra Mundial. Com a prática do esporte a mulher torna-se esguia, esbelta e moderna o que pode se relacionar com o movimento artístico nascente, o modernismo (LIPOVETSKY, 2009, p. 89).

Segundo Mary Del Priore (2000, p. 64) no Brasil as mulheres passam a se exercitar no período da República acompanhando assim as mudanças ocorridas nas cidades para se assemelharem as capitais europeias. A prática dos exercícios vinha para combater o ócio e o hábitos mundanos da juventude, além da perseguição aos "quilinhos a mais". Era escrito na revista Sports os exercícios que mais convinham as mulheres, que segundo eles são os que aumentam a flexibilidade e a destreza da coluna vertebral, práticas higiênicas e estéticas que desenvolvam a parte inferior do corpo. Nos periódicos também se exaltava e incentivava a prática esportiva, por exemplo na edição 25 do Jornal das Moças foi escrito que 
os elegantes antigos sempre se entregaram com ardor a toda a sorte de sports. E nada mais natural. Os exercícios desenvolvem o corpo, tornando-o assim mais bello. Não há belleza sem saúde. D'ahi a elegância, nascida da saúde, portanto amiga dos sports.

Pode-se destacar que as revistas femininas não só fizeram referência as roupas que deveriam usar como também ao corpo adequado para fazê-lo e o que seria necessário para alcançá-lo mantendo a feminilidade. Tudo o que na época poderia interferir ou melhorar, dicas em geral para a vida das mulheres estava contido nas revistas femininas em circulação no momento contemplado nesse estudo.

\section{Leitura feminina: Jornal das Moças}

Nessa pesquisa a fonte utilizada é o Jornal das Moças que além de revelar as vestimentas por meio dos desenhos publicados também traz artigos com sugestões e descrições dos fatos mundiais que afetaram a confecção e o estilo das roupas. Usando essa fonte não só podemos analisar a indumentária do período privilegiado nesse estudo como é possível ter ideia de como estava a imprensa brasileira dirigida para mulheres.

O reconhecimento da imprensa como importante fonte histórica tem nos presenteado com a possibilidade de resgatar momentos passados do cenário da nossa vida cotidiana. A imprensa registra, comenta, forma opiniões, distrai; através de suas palavras e imagens reencontramos valores e comportamentos perdidos. A consciência dessa riqueza documental fez aumentar a quantidade de estudos que usam a imprensa como suporte; desses olhares, porém, são em menor número os que se voltam a uma modalidade presente desde o início do séc. XIX: a imprensa feminina (LIMA, 2007, p. 222). 
O Jornal das Moças circulou semanalmente pelas principais capitais brasileiras de 1914 a 1965, tinha o objetivo de ser "a revista de maior penetração no lar" e como outras revistas femininas se inspirava nos grandes magazines de variedades impressos na Europa, sobretudo os franceses (OLIVEIRA; SILVEIRA, 2016, p. 48). Por mais que levasse o nome de Jornal era considerado uma revista por conter assuntos variados destinado ao entretenimento das mulheres.

Sendo assim, e de maneira análoga a revista Fon-Fon, a Jornal das Moças constituía-se, para suas leitoras, em um grande manual de boas maneiras, mesmo que, por vezes, abordasse questões ligadas a atualidade da capital carioca e temas relevantes para apreensão da situação geral do país, como economia, cultura e política (OLIVEIRA; SILVEIRA, 2016, p. 49).

Nesse estudo será contemplado apenas a análise das seções Modos e Modas e A arte de ser elegante pois tratam diretamente do assunto moda. A determinação do que estaria em alta vinha de Paris e no Brasil algumas adaptações eram necessárias para seguir as tendências. Como foi escrito na edição 11 do jornal em 15 de outubro de 1914 "podemos portanto crear a nossa moda única: a moda de verão, pois ao contrario do que sucede com a Greenlandia [...] nós somos o paiz do verão quasi eterno".

O público feminino desde o início do século XX teve mais espaço para desenvolver seu habito de leitura devido a intenção do Brasil de se desenvolver e comparar aos países europeus, assim a leitura foi considerada uma forma de disciplinar e civilizar o indivíduo (ALMEIDA, 2014, p. 10). As mulheres obtiveram autorização para circular nos salões de leitura e as publicações para esse novo público aumentava cada vez mais, porém existia a preocupação do que estaria escrito nesses materiais, as mulheres só eram permitidas a

leitura solitária de romances e livros de civilidade; a leitura coletiva de folhetins encartados em jornais e revistas, durante serões de família; assim como a leitura de conselhos sobre moda, higiene, culinária, saúde das crianças e culinária, sonetos, crônica social, 
contos, piadas publicadas em revistas femininas. À mulher do novo século eram consentidas diversas leituras (ALMEIDA, 2014, p. 6).

O Jornal das Moças era uma revista destinado as pertencentes das classes alta e média, é possível perceber isso pelo preço da revista e pelos anunciantes que ali faziam suas propagandas, os produtos eram destinados para famílias abastadas e facilitariam a vida da dona de casa. A mulher brasileira do início do século XX era vista como esposa e mãe e só poderia trabalhar em funções que fossem da extensão do seu lar como professora ou enfermeira (ALMEIDA, 2014, p. 7), somente nesse período elas começaram a receber uma formação educacional próxima a oferecida aos homens, o percentual de mulheres alfabetizadas foi aumentando. A leitura das revistas femininas tem um espaço fundamental nessa transformação pois serviam como lazer mais também como função pedagógica na tentativa se suprir a falta de uma educação realmente formalizada (OLIVEIRA; SILVEIRA, 2016, p. 54).

Algo que deve ser ressaltado nesse momento é que a capital do país, Rio de Janeiro, passava por grandes transformações para se assemelhar a Paris, a influência francesa na cidade é inegável tanto pelas roupas, costumes, mas também pela organização social e urbana. O período conhecido como Belle Époque no Brasil estende-se de 1898 a 1914, engloba da eleição de Campos Salles a Primeira Guerra Mundial (NEEDELL apud MACENA, 2010, p. 16). Com a eleição de Pereira Passos como prefeito da capital federal a tentativa de "modernizar" o Rio de Janeiro ganha forma, o bota abaixo, a revolta da vacina, acontecimentos estudados na escola durante o $9^{\circ}$ do ensino fundamental e $3^{\circ}$ ano do ensino médio estão entre acontecimentos relevantes do período.

A derrubada dos cortiços e casebres do centro da cidade, a construção dos grandes boulevards, a marginalização da população de baixa renda e a vacinação obrigatória para extinção de doenças que atrapalhavam o turismo e os negócios internacionais estão no centro do período estudado e possuem impacto na imprensa feminina da época. 
No séc. $X X$, as transformações que afetaram a sociedade brasileira, principalmente no Rio de Janeiro e São Paulo, trazendo crescimento urbano, aumento da população e de suas camadas médias, melhoria no nível de instrução, entre outras modificações, refletiram-se na modernização da imprensa. Surgiu a grande imprensa, com maiores tiragens, sustentadas pela publicidade. Intensificouse o hábito de leitura de jornais e revistas, conforme comprova o aumento das publicações (LIMA, 2007, p. 224).

As revistas femininas entre elas a Jornal das Moças têm suas publicações influenciadas por esses acontecimentos e claro pela constante influência francesa, além do princípio de reconhecimento da mulher como um indivíduo único, porém que deve tomar cuidado não só com o que veste, mas com a aparência em geral. Na edição 17 do dia 15 de janeiro de 1915 foi escrito que "a elegância reside na Belleza, na perfeição das linhas, no contorno de um busto de elance deslumbrante, num rosto sem rugas, num movimento de andar, e num gesto.

Outro acontecimento de grande impacto do período estudado é a Primeira Guerra Mundial, que logo de início não teve grande reflexo nas roupas pois a coleção de 1914 já estava em produção, no entanto no decorrer do conflito as vestimentas foram se transformando para se adequar ao período catastrófico que assolava a Europa, e os efeitos também foram vistos no Brasil. Por exemplo na edição 27 do Jornal das Moças foi dito que "a guerra tem influído muito nos novos modelos de vestuários não só femininos como masculinos. Os vistosos uniformes militares tem sido imitados, quase que copiados."

A guerra teve uma continua influência sobre a moda não só pelos uniformes militares adaptados as vestimentas civis, como os tailleurs, mas o luto das mulheres que perderam seus parentes gerou coleções especificas para esse momento de profunda tristeza. No Jornal na edição 111 foi colocado que "uma senhora não deve, mesmo no decurso de um longo lucto, abandonar seus hábitos elegantes. $\mathrm{O}$ melhor é se conformar, quanto a severidade do lucto [...] e as exigências da vida 
que leva." Os acessórios também ganharam nova roupagem com a guerra, a edição 37 publicou na seção Modas e Modos

A única novidade, actualmente em Paris, consiste no uso de joias feitas com estilhaços de granadas e outros projectos de guerra, e que tem tido um êxito completo. Não se trata de joias compradas ao acaso, mas de uma joia pessoal, uma espécie de relíquia que encerre uma recordação saudosa e grata para quem a possue (Jornal das Moças, 1915).

A Primeira Guerra trouxe a escassez inclusive de tecidos pois havia a dificuldade de obtê-lo e também a demanda privilegiada era a do campo de batalha, as cores vibrantes deram lugar as cores neutras. As vestimentas femininas encurtaram e permitiram a mulher se locomover com mais facilidade, afinal agora a mão de obra delas era necessária nas fábricas de armamentos e também no cultivo do campo.

A guerra trouxe anos de sobriedade mais com o seu fim as roupas continuaram se encurtando, as mulheres se posicionaram como provedoras da família e exigiam o direito a participação política, afinal como destaca Pires e Silva (2018, p. 60) dos comportamentos escolhidos pela mulher, a indumentária se mostra como o melhor caminho para refletir a decisão feminina.

A moda nos traz a perspectiva de estudar as relações sociais e as características da sua evolução, as pernas das mulheres escondidas até a Primeira Guerra Mundial e depois exposta em saias de comprimento no joelho são fatos que trazem reflexões de como isso aconteceu, por que mudaram, qual o contexto envolvido para a mudança.

\section{Moda e ensino: uma perspectiva}

No livro de Daniela Calanca (2008, p. 16) foi verificado que a indumentária é um fenômeno completo porque, além de propiciar um discurso histórico, econômico, etnológico e tecnológico, também tem valência de linguagem. E a roupa a partir do momento que reveste o 
corpo pode ser compreendida como linguagem do corpo. Gilda de Mello e Souza (1987, p. 29) complementa afirmando que a moda serve a estrutura social, acentuando a divisão em classe, exprime ideias e sentimentos pois é uma linguagem.

No período contemplado por este estudo a moda não é só um separador de classes mais também de sexos, as roupas masculinas e femininas a partir do momento que homem começou a usar calça e casaco tomou uma distância. A masculina manteve-se estável já a feminina sofre constantes transformações e é a mais impactada pelos acontecimentos mundiais descritos acima (transformações no Rio de Janeiro e Primeira Guerra Mundial). Segundo Daniel Roche (2007, p. 56) as roupas significam muito mais do que aparentam, as roupas são como as palavras de uma língua, que precisam ser explicadas e traduzidas, a dificuldade de fazer está em apreender em um mesmo movimento a estabilidade e as mudanças das aparências.

Utilizando as nuances da moda como possibilidade para estudar história espera-se conseguir estabelecer com alunos a relação entre os fatos estudados na disciplina de História e a modificação que as roupas sofrem nesse momento e que são traduzidas nos desenhos e artigos publicados em uma das revistas femininas em de grande circulação nacional que era a Jornal das Moças. Revista essa que está digitalizada e, portanto, os alunos conseguirão acessar de qualquer lugar e fazer suas próprias constatações a partir dos conteúdos trabalhados em sala.

Com esse contato próximo com a fonte histórica o aluno teria mais interesse em interagir com ela (ECCO, 2007, p. 132) e esse contato seria transformado em investigação com observação voltada para aquilo que impacta a discussão e a produção do conhecimento. No artigo produzido pela professora Kátia Simioni Martins Bodan (2014, p. 5) afirma-se que o uso da análise documental pode colaborar para que o aluno busque referências sobre o tema abordado, realize leitura qualificada do material, relacione diferentes temporalidades, demarque aspectos comparativos entre as fontes analisadas, e, assim estabeleça relações com seu cotidiano. 
Nesse estudo partimos da perspectiva que a análise da vestimenta de um determinado período pode trazer ao aluno a curiosidade de refletir também sobre a constituição da sua própria roupa, como surgem os estilos que estão em alta, onde ele se inspira e qual a origem dessa roupa e inspiração, podendo assim elaborar seus pensamentos para seu contexto de vida e o da sociedade que habita.

Encarando a moda como um princípio de leitura social podemos usar suas gravuras e artigos publicados no Jornal das Moças para analisar e tentar interpretar os conflitos decorrentes de 1914 a 1916 . O uso de imagens em sala de aula traz a possibilidade de interpretação da história com riqueza de informações e detalhes, afinal as imagens não devem ser consideradas simples reflexos de sua época, mas extensões de contextos sociais em que foram produzidas (BURKE apud LITZ, 2008, p. 16).

\section{Considerações finais}

Com as fontes pesquisadas para construir essa pesquisa podemos afirmar que existe embasamento teórico para relacionar o estudo da moda com o estudo da história. Várias perspectivas sobre a produção de moda podem ser adotadas para análise histórica das roupas, mas o que interessa aqui são as transformações das roupas registradas pelo periódico Jornal das Moças, essa revista que é a fonte principal da pesquisa e possibilita uma reflexão sobre a sociedade que a produziu.

O ensino de história para adolescentes também permite diferentes tipos de abordagem, nesse estudo a proposta de utilizar a moda vem exatamente porque de todas as possibilidades ela quase nunca é lembrada mesmo podendo oferecer uma riqueza de ligações entre os alunos e a disciplina estudada. A temporalidade escolhida traz o início da aceleração das mudanças não só nas vestimentas mais também na sociedade como um todo, novas oportunidades começam a aparecer cada vez mais rápido e existe uma dificuldade de se manter 
sempre atualizado, por isso a demanda por periódicos foi crescente ano após ano.

Mesmo com a Primeira Guerra Mundial em curso percebemos que a moda não parou, ela se adaptou ao novo momento traduzindo o sofrimento da guerra, a homenagem aos soldados com as referências militares nas roupas, mas em outras coleções retomavam a leveza das linhas para tentar fugir do horror daquele conflito.

Como disse Gilda de Mello e Souza (1987, p. 51) não é possível estudar uma arte, tão comprometida pelas injunções sociais como é a moda, focalizando a apenas nos seus elementos estéticos. Para que possamos compreender em toda a riqueza, devemos inseri-la no seu momento e no seu tempo, tentando descobrir as ligações ocultas que mantem com a sociedade. E é nessa intenção de ligar a moda com o contexto que foi produzida no início do século XX que este foi produzido.

\section{Referências}

ALMEIDA, Nukácia Araújo de. Revistas femininas e educação da mulher: o jornal das moças. Anais do Simpósio ALB, 2014.

ANDRADE, Rita M. de. Historicizar indumentária (e moda) a partir do estudo de artefatos: reflexões acerca da disseminação de práticas de pesquisa e ensino no Brasil. Moda Palavra e-periódico, n. 14, p. 72-82, jul./dez. 2014.

BESSONE, T. As leitoras no Rio de Janeiro do século XIX: a difusão da literatura. Gênero, v. 5, n. 2, p. 81-93, 2005.

BONDAN, Kátia Simioni Martins. Metodologias diversificadas para o ensino de História: cotidiano, formas de vestir, comer e narrar na antiguidade romana. In: PARANÁ. Secretaria de Estado da Educação. Superintendência de Educação. Os Desafios da Escola Pública Paranaense na Perspectiva do Professor PDE: Produção Didático-pedagógica, 2014. Curitiba: SEED/PR., 2016. V.2. (Cadernos PDE). 
CALANCA, Daniela. História social da moda. Tradução de Renato Ambrosio. São Paulo: Editora Senac, 2008.

CARVALHO, K. de. A imprensa feminina no Rio de Janeiro, anos 20: um sistema de informação cultural. Ciência da Informação, Brasília, v. 24, n. 1, p. 1-11, 1995.

DEBOM, Paulo. A moda como objeto de pensamento. Veredas da história, v. 9, n. 1, p. 23-47. 2016.

DEL PRIORE, Mary. Corpo a corpo com a mulher: pequena história das transformações do corpo feminino no Brasil. São Paulo: Editora Senac São Paulo, 2000.

ECCO, Idanir. $\mathrm{O}$ ensino de história: evidências e tendências atuais. $R$. ciências humanas, v. 8, n. 10, p. 123-141, jun. 2007.

JORNAL DAS MOÇAS. Rio de Janeiro. Menezes, Filho \& C. Ltda. 19141920.

LAMOGLIA, Adriana F. A moda como elemento de distinção e imitação na contemporaneidade. Revista Espaço Acadêmico, n. 191, abr. 2017.

LAVER, James. A roupa e a moda: uma história concisa. Tradução de Glória Maria de Mello Carvalho. São Paulo: Companhia das Letras, 1989.

LIMA, S. L. L. Imprensa feminina, revista feminina: a imprensa feminina no Brasil. Projeto História, São Paulo, n. 35, p. 221-240, dez. 2007.

LITZ, Valesca Giordano. O uso da imagem no ensino de história. In: PARANÁ. Secretária de Estado da Educação. Superintendência da Educação. Curitiba: SEED/PR, 2009.

MACENA, F. F. Madames, mademoiselles, melindrosas: "feminino" e modernidade na revista Fon-Fon!. 2010. 128 f. Dissertação (Mestrado em História) - Programa de Pós-Graduação em História, Universidade de Brasília, Brasília, 2010.

MENDES, Valerie D. A moda do século XX: 280 ilustrações, 66 em cores. Tradução de Luis Carlos Borges. 2. ed. São Paulo: Martins Fontes, 2009. 
NERY, Marie Louise. A evolução da indumentária: subsídios para a criação de figurino. 5 reimp. Rio de Janeiro: Ed. Senac nacional, 2013.

OLIVEIRA, N. P; SILVEIRA, F. J. N. Mulheres cariocas e práticas de leitura nos anos de 1920: um estudo documental a partir das revistas Fon-Fon e Jornal das Moças. Perspectivas em ciência da informação, v. 21, n. 2, p. 33-60, abr./jun. 2016.

PIRES, D.; SILVA, S. R. A. A moda em tempos de guerra: da saia sino à androgenia. Revista eletrônica de moda, v 6, n. 1, p. 49-68, set. 2018.

ROCHE, Daniel. A cultura das aparências: uma história da indumentária (séculos XVII-XVIII). Tradução de Assef Kfouri. São Paulo: Editora Senac São Paulo, 2007.

SOUZA, Gilda de Mello e. O espirito das roupas: a moda no século dezenove. São Paulo: Companhia das letras, 1987.

SVENDSEN, Lars. Moda: uma filosofia. Tradução de Maria Luisa X. de A. Borges. Rio de Janeiro: Zahar, 2010.

ZANON, M. C. Fon-Fon!: um registro da vida mundana no Rio de Janeiro da Belle Époque. Patrimônio e Memória, v. 1, n. 2, p. 18-30, 2005. 